\title{
Sudden death after operative repair of tetralogy of Fallot
}

\author{
JOSE MARIN-GARCIA 1 AND JAMES H. MOLLER \\ From the Department of Pediatrics and the Dwan Cardiovascular Learning Center, \\ University of Minnesota, Minneapolis, U.S.A.
}

The clinical and necropsy findings in 3 patients with tetralogy of Fallot who died suddenly after corrective operation are presented. Early postoperative electrocardiograms of 2 patients showed coexistent right bundlebranch block and left anterior hemiblock; one of these developed complete atrioventricular block and required a pacemaker. In the third patient, postoperative electrocardiograms showed anterior myocardial infarction. At necropsy, there was gross and histological evidence of myocardial infarction in each patient. After operation, extensive myocardial fibrosis and the development of right bundle-branch block and left anterior hemiblock are possible factors causing cardiac arrhythmias and sudden death.

Sudden death has been reported after corrective surgery of tetralogy of Fallot and is related to the development of conduction disturbances in the divisions of His bundle. We have seen 3 such patients with tetralogy of Fallot; each died more than 6 months after complete repair of the anomaly and in each a healed myocardial infarction was found at necropsy. The preoperative electrocardiogram in each case was typical of tetralogy of Fallot. After operation, the electrocardiograms of one patient showed the pattern of anterior myocardial infarction. The electrocardiograms of the other 2 patients showed left axis deviation and complete right bundle-branch block; while this pattern has been observed in postoperative electrocardiograms in association with the subsequent development of complete heart block and sudden death, we wish to describe the finding of myocardial infarction in such patients.

\section{Case reports}

\section{CASE 1}

This 8-year-old boy was diagnosed as tetralogy of Fallot at the age of 4 years, and a right BlalockTaussig shunt was performed. At the age of 7 years, at operation for complete correction of his cardiac anomaly, infundibular muscle was resected through a longitudinal ventriculotomy, the ventricular septal

'Present address: Department of Pediatrics, St. Louis University School of Medicine, St. Louis, MI 63104.

Received for publication 21 February 1977 defect was closed by a 'teflon' patch, and a pulmonary valvotomy was performed. Though he required a tracheostomy in the immediate postoperative period, he made good progress after this. The postoperative electrocardiogram (Fig. 1) showed abnormal $Q$ waves in praecordial leads V4R to V5, suggestive of extensive anterior myocardial infarction. The patient was taking digitalis at the time of discharge, but this was later discontinued. Subsequently, the patient attended school and was able to play without dyspnoea or cyanosis. He still had a grade $2 / 6$ systolic ejection murmur at the upper left sternal border. He died suddenly, 9 months after operation, while playing at home.

\section{Necropsy findings}

The external surface of the heart showed healed fibrous pericarditis. The interior of the right and left atria was normal. The right ventricle was slightly dilated. An anomalous muscle bundle ran from the anterior wall of the ventricle to the septal band but did not appear obstructive. There was conspicuous endocardial sclerosis of the right ventricular outflow tract and the septal wall of the right ventricle. The anterior wall of the right ventricle was thinned and scarred along the ventriculotomy incision. No residual ventricular septal defect or outflow obstruction was present. The pulmonary valve was tricuspid, each cusp being thickened.

In the anterior wall of the left ventricle and the ventricular septum, there was an oval healed transmural myocardial infarction, measuring $6.0 \times 4.0$ 


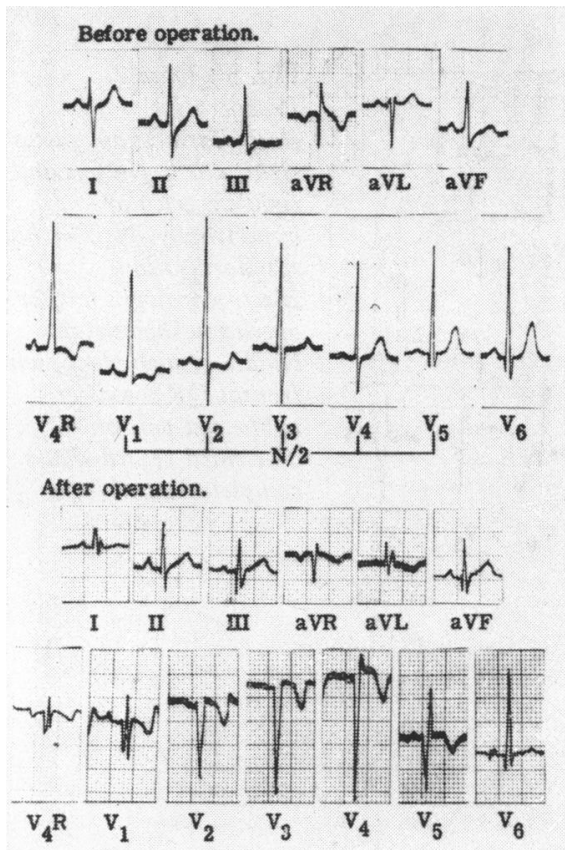

Fig. 1 Case 1. Preoperative electrocardiogram shows $Q R S$ axis $+120^{\circ}$ and right ventricular hypertrophy. $\mathrm{N} / 2=$ half standardisation. Postoperative electrocardiogram shows deep $Q$ waves and inverted $T$ waves in praecordial leads, indicating anterior myocardial infarction.

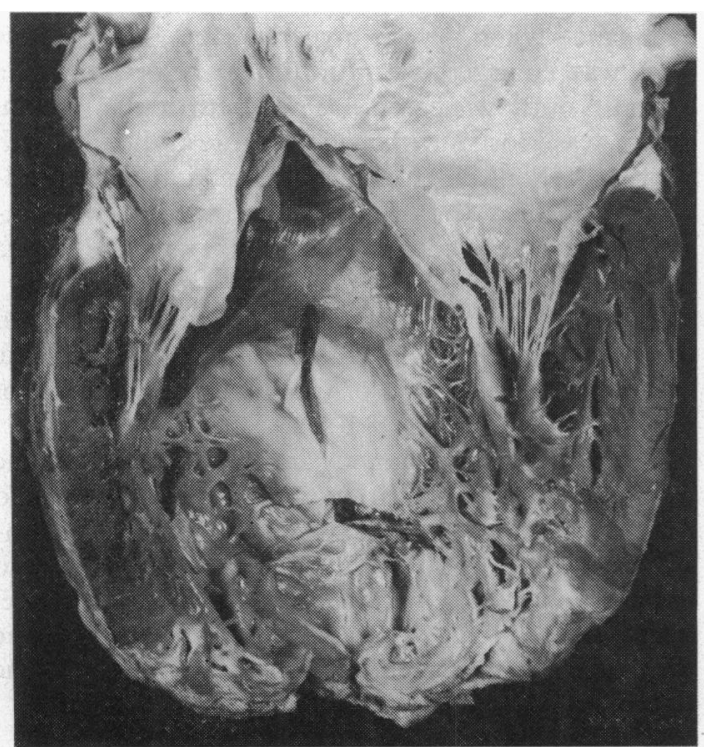

Fig. 2 Case 1. Left atrium and left ventricle. Thickened white endocardium over ventricular septum. Apex of ventricle thinned. cm (Fig. 2). The ventricular septum was thinned and the endocardium covering the infarcted area was thickened. In addition, the apical region of the left ventricle showed myocardial scarring. Both sides of the patch covering the ventricular septal defect were covered with thick, fibrous tissue. The origin and distribution of the coronary arteries were normal. The right branch of the left anterior descending coronary artery was involved in the fibrous tissue and sutured in the region of the right ventriculotomy.

Microscopical examination of the ventricular septum and the anterior wall of the left ventricle showed extensive fibrosis with replacement of the myocardium by bands of fibrous tissue and collagen. There was proliferative endocardial fibrosis, especially on the right ventricular surface of the ventricular septum.

CASE 2

In this 14-year-old boy the diagnosis of tetralogy of Fallot was made in infancy, and a left BlalockTaussig shunt was performed at the age of 3 years. At the age of 13 years, he had a corrective operation. A vertical right ventriculotomy was performed, since an unusually prominent branch of the right coronary artery lay across the right ventricular infundibulum. The infundibular obstruction was resected and the ventricular septal defect was closed with a 'teflon' patch. A pulmonary valvotomy was performed, and a constricting band immediately below the pulmonary annulus was also excised.

At the end of the operation, the patient appeared to be in nodal rhythm, but sinus rhythm returned spontaneously. Complete atrioventricular dissociation was noted in the first $\mathbf{4 8}$ hours after the operation, but again sinus rhythm returned spontaneously. The postoperative electrocardiogram showed complete right bundle-branch block. The mean frontal plane QRS axis of the unblocked portion of the QRS complex was $-90^{\circ}$ (Fig. 3).

The patient remained well for 9 months, but was then found to be in complete heart block and a pacemaker was implanted. Five months later, the pacemaker wire was broken during an automobile accident. After repair of the wire, the patient was admitted repeatedly for infection of the pacemaker pocket and pacemaker malfunction. A new set of myocardial electrodes and pacemaker were implanted. Seven days later, death occurred from ventricular fibrillation.

Necropsy findings

The heart was much enlarged and showed evidence of healed, fibrous pericarditis. The right atrium and 


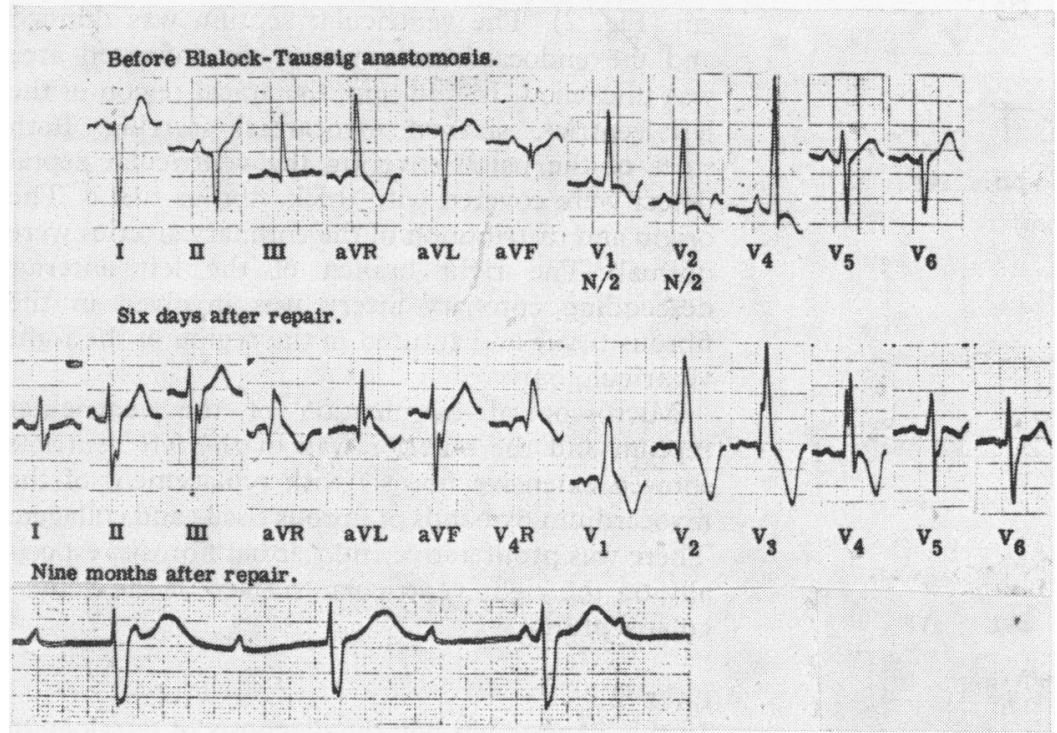

Fig. 3 Case 2.

Preoperative electrocardiogram shows right axis deviation and right ventricular hypertrophy. $N / 2=$ half standardisation.

Electrocardiogram after operation shows right bundle-branch block, with frontal $Q R S$ axis of unblocked portion $-90^{\circ}$. The third record shows complete heart block. right ventricle were dilated. The septal leaflet of the tricuspid valve showed thickened, fused chordinae tendineae. In the inflow region the wall thickness of the right ventricle was $1.2 \mathrm{~mm}$, while proximal to the infundibular region this was $5 \mathrm{~mm}$. The endocardium of the right ventricle showed generalised thickening, particularly in the region of the closed ventricular septal defect and the outflow tract. There was no residual outflow obstruction and no residual ventricular septal defect. The pulmonary valve was bicuspid and dysplastic. A circumferential fibrous ring in the pulmonary trunk created supravalvar stenosis.

The left atrium and the mitral valve were normal. The left ventricle showed hypertrophied walls and endocardial thickening, the latter being greater in the subaortic region. The origin and distribution of the coronary arteries were normal. The aortic arch was right sided with mirror-image branching.

Microscopical examination of the outflow position of the right ventricle showed extensive transmural myocardial infarction with endocardial and pericardial fibrosis (Fig. 4). Occasional foreign body giant cells were seen around the suture material. A moderate amount of fibrosis was present in the ventricular septum. Except for pericarditis and some epicarditis, the myocardium of the left ventricle was normal. Sections along the course of the bundle of $\mathrm{His}$ and the atrioventricular node showed fibrous strands intermingling with these structures, and in some areas densely surrounding them.

\section{CASE 3}

This 6-year-old boy was first seen at the age of $3 \frac{1}{2}$ months because of severe cyanosis. A diagnosis of tetralogy of Fallot was made and a Brock pulmonary valvotomy was performed. At the age of 4 years, cardiac catheterisation and right ventriculogram showed tetralogy of Fallot with a long area of infundibular narrowing. Complete correction was performed when he was 6 years of age. The outflow tract was enlarged by infundibular resection and a 'teflon' outflow patch. The ventricular septal defect was closed with considerable difficulty with another 'teflon' patch. During resection of infundibular muscle, the ventricular septum was inadvertently incised in the region of the crista supraventricularis.

The electrocardiogram after the operation showed complete right bundle-branch block (Fig. 5). The frontal plane QRS axis of the unblocked portion of the QRS complex was $-105^{\circ}$.

The patient remained in congestive cardiac failure after the operation and required repeated hospital admissions. Physical findings were consistent with a residual ventricular septal defect and angiocardiographic studies confirmed its presence. The patient died after cardiac arrest, while in the hospital for management of congestive cardiac failure, 10 months after the corrective operation.

\section{Necropsy findings}

The external surface of the heart showed healed pericarditis. The right atrium was slightly dilated 


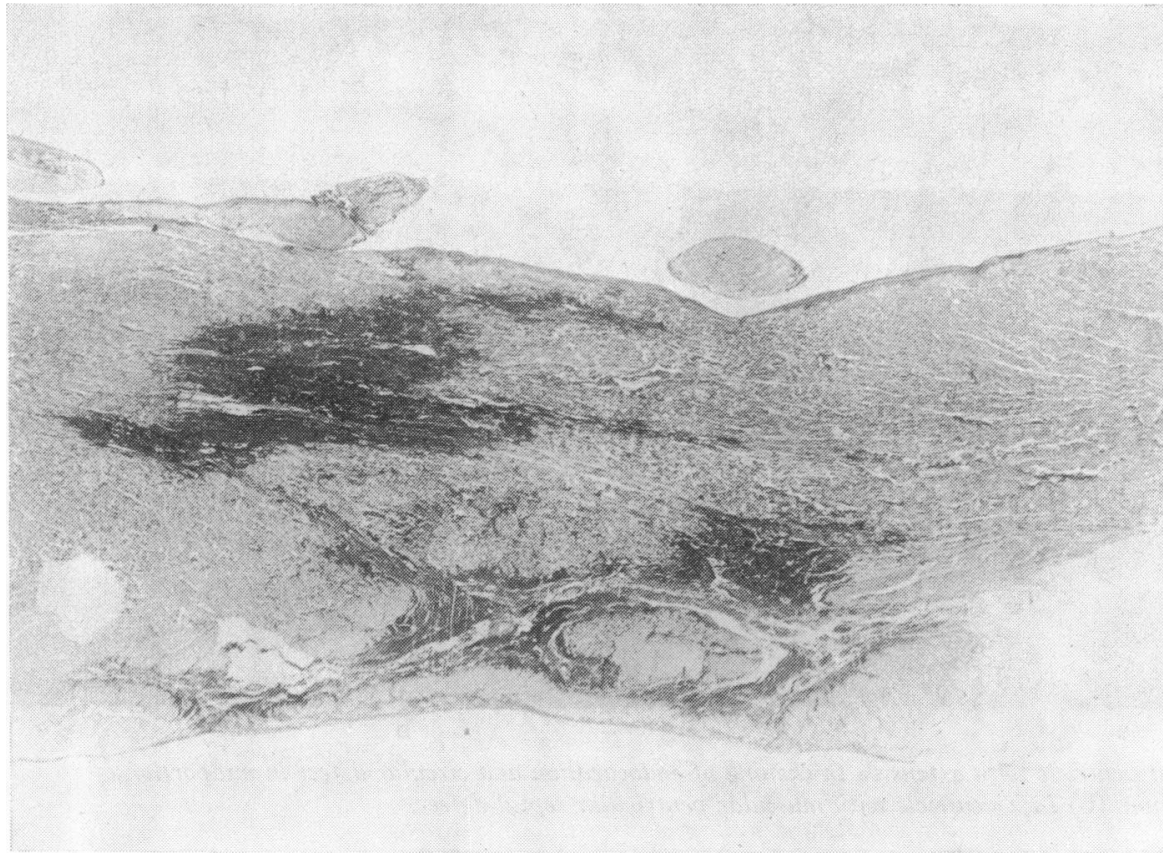

Fig. 4 Case 2.

Extensive fibrosis of right

ventricular

myocardium.

$(\times 4 \cdot 2$.

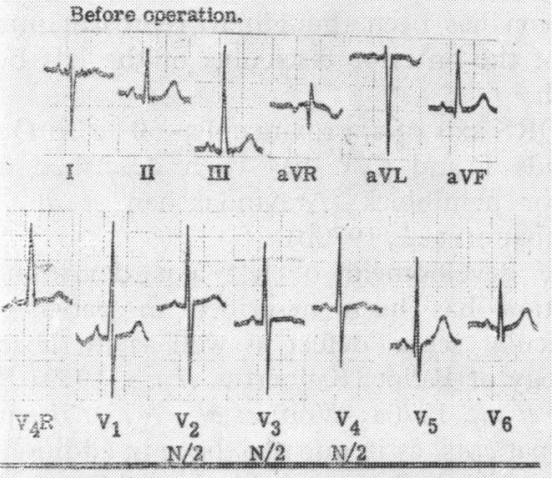

Tive months after operation.

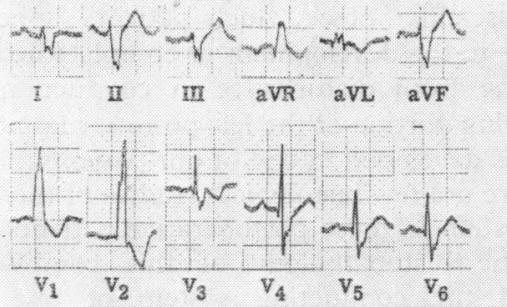

Fig. 5 Case 3. Preoperative electrocardiogram shows $Q R S$ axis $+120^{\circ}$ and right ventricular hypertrophy $(N / 2=$ half standardisation). Postoperative electrocardiogram shows complete right burdle-branch block and left axis deviation. and the left atrium was normal. The anterior and septal walls of the right ventricle showed extensive scarring that extended into the outflow tract (Fig. 6a). There was no residual right ventricular outflow obstruction. The ventricular septal defect had been incompletely closed and measured $12 \times 4 \mathrm{~mm}$. The anterior portion of the ventricular septum was very thin, from about $2 \mathrm{~cm}$ below the pulmonary valve to the apex, and there was an $8 \times 5 \mathrm{~mm}$ interventricular communication in this part of the septum. The pulmonary valve was bicuspid and thickened.

The left ventricular cavity was dilated, and there was endocardial thickening involving the septal wall and the region of the apex (Fig. 6b). The endocardial thickening extended to the subaortic region. The anterior interventricular communication in the muscular septum was surrounded by extensive scarring and thinning of the septum. In addition, there was scarring of the left ventricular wall in the region of the apex. The origin and distribution of the coronary arteries were normal.

Microscopical examination of the ventricular septum showed extensive fibrosis in the region of the infarcted area. Some of the intramyocardial branches of the coronary arteries showed proliferative intimal fibrosis. There was mild scarring of the free wall of the left ventricle. 


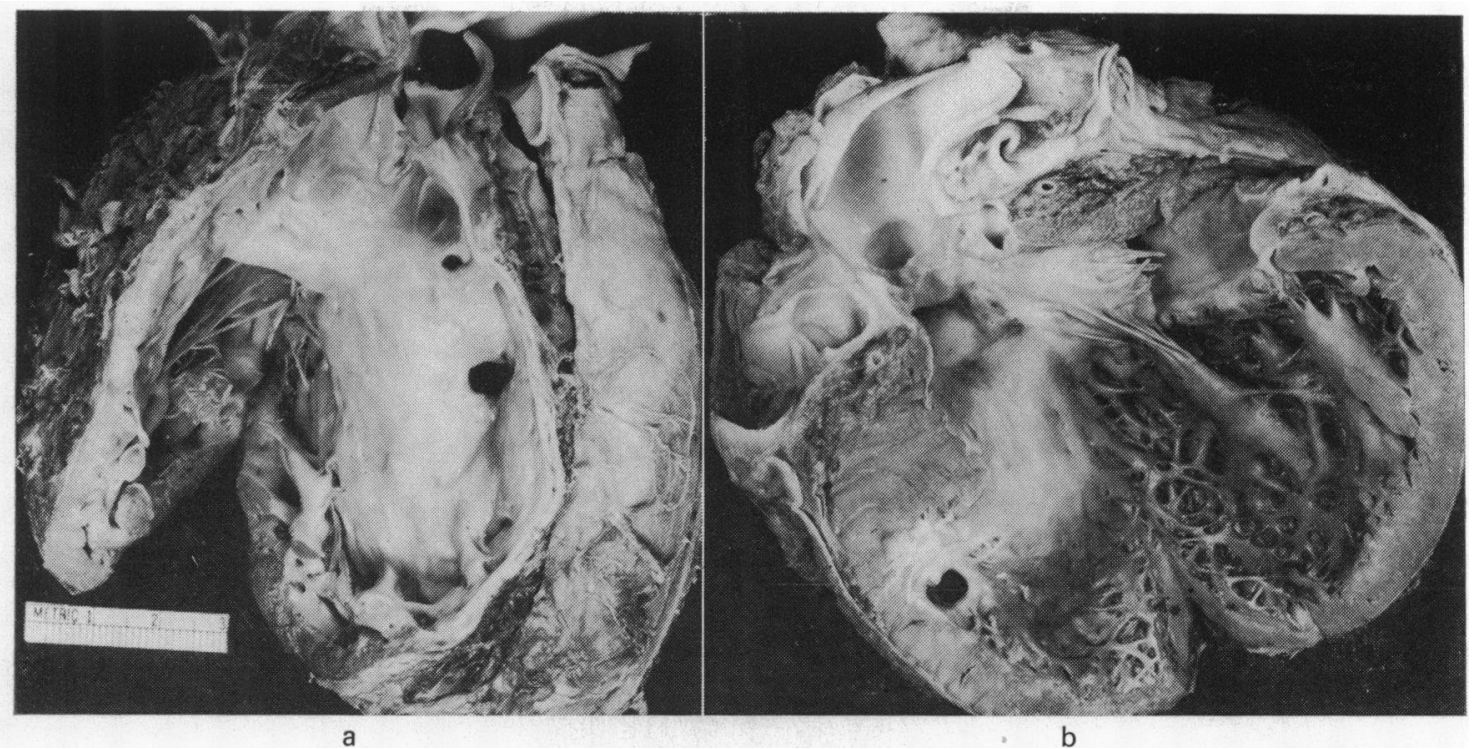

Fig. 6 Case 3. (a) Right ventricle with extensive thickening of endocardium and circular defect in midportion of muscular ventricular septum. (b) Left ventricle with muscular ventricular septal defect.

\section{Discussion}

Ischaemic necrosis of the myocardium and interruption of the conduction bundles have been reported after right ventriculotomy and closure of ventricular septal defect (Korns et al., 1969; Kulbertus et al., 1969; Gelband et al., 1971). The myocardial necrosis has been thought to be related to surgical division of the coronary arteries which show an anomalous distribution over the outflow area of the right ventricle. Our study indicated, however, that it is not necessary for distribution of the branches of the coronary arteries to be abnormal for myocardial infarction to occur after operation in patients with tetralogy of Fallot.

Extensive fibrosis of the ventricular septum and anterior wall of the right ventricle was seen in all our patients, each of whom showed a normal coronary arterial distribution. These patients died unexpectedly, though each showed an electrocardiographic abnormality: this was coexistent left axis deviation and complete right bundle-branch block in cases 2 and 3, with the later development of complete heart block in case 2, and an anterior myocardial infarct pattern in case 1 .

Grant (1956) first pointed out that a superior orientation of the QRS complex may be seen in patients with coronary arterial disease and anterolateral myocardial infarction. Later, the presence of a similar QRS pattern was described in patients with extensive myocardial fibrosis but without coronary arterial disease (Banta et al., 1964). Left axis deviation has thus been related to fibrosis in the left ventricle. More recently, however, left axis deviation has been thought to represent interruption of the anterior fasciculus of the left bundlebranch.

A QRS axis of approximately $-60^{\circ}$ with $Q$ waves in leads $I$ and aVL has been described as left anterior hemiblock (Aravindakshan et al., 1970; Rosenbaum et al., 1970b).

The development of left axis deviation after operation has been described in patients with ventricular septal defect as well as in those with tetralogy of Fallot (Kulbertus et al., 1969; Rosenbaum et al., 1970a; Wolff et al., 1972). Frequently these patients, as in our two, have in addition complete right bundle-branch block, yielding a pattern of bifascicular block. Such patients appear vulnerable to the development of complete heart block resulting from disturbance in conduction of the remaining portion of the left posterior fasciculus, as perhaps developed in one of our patients.

There are few histological studies of the conduction system in these postoperative patients to indicate the histopathology of this condition. We studied the conducting system of one of our patients (case 2) and found fibrous strands in the atrioventricular node and bundle of $\mathrm{His}$ and surrounding tissue; there was, however, no actual interruption of the conducting system.

Death was sudden in our 3 patients and ventri- 
cular arrhythmias are presumed to have been the cause. In the 2 patients with a combination of right bundle-branch block and left anterior hemiblock, death could be explained by progression to complete heart block and related arrhythmias, including cardiac standstill. In the other patient (case 1), with electrocardiographic evidence of myocardial infarction, myocardial damage with resulting fibrosis may have been responsible for arrhythmias, as in patients with coronary disease dying suddenly after myocardial infarction without conduction disturbances. It is not possible to determine from our study whether the arrhythmias and consequent sudden death were directly related to injury of the conduction tissue, resulting in right bundlebranch block and left anterior hemiblock in two cases, or to myocardial damage (infarction), or to both.

Finally, we recommend close electrocardiographic control in the follow-up of patients who develop right bundle-branch block and left anterior hemiblock, with or without atrioventricular conduction disturbances, or a myocardial infarction pattern, after complete correction.

\section{References}

Aravindakshan, V., Elizari, M. V., and Rosenbaum, M. B. (1970). Right bundle-branch block and left anterior fascicular block (left anterior hemiblock) following tricuspid valve replacement. Circulation, 42, 895-902.
Banta, H. D., Greenfield, J. C., Jr., and Estes, E. H., Jr. (1964). Left axis deviation. American fournal of Cardiology, 14, 330-338.

Gelband, H., Waldo, A. L., Kaiser, G. A., Bowman, F. O., Jr., Malm, J. R., and Hoffman, B. F. (1971). Etiology of right bundle-branch block in patients undergoing total correction of tetralogy of Fallot. Circulation, 44, 1022-1033.

Grant, R. P. (1956). Left axis deviation. An electrocardiographic-pathologic correlation study. Circulation, 14, 233-249.

Korns, M. E., Schwartz, C. J., Edwards, J. E., and Lillehei, C. W. (1969). Pathologic sequelae and complications of ventriculotomy. I. With special reference to the myocardium. Archives of Pathology, 88, 269-283.

Kulbertus, H. E., Coyne, J. J., and Hallidie-Smith, K. A. (1969). Conduction disturbances before and after surgical closure of ventricular septal defect. American Heart fournal, 77, 123-131.

Rosenbaum, M. B., Corrado, G., Oliveri, R., Castellanos, A., Jr., and Elizari, M. V. (1970a). Right bundle branch block with left anterior hemiblock surgically induced in tetralogy of Fallot. Relation to the mechanism of electrocardiographic changes in endocardial cushion defects. American fournal of Cardiology, 26, 12-19.

Rosenbaum, M. B., Elizari, M. V., and Lazzari, J. O. (1970b). The Hemiblocks. Tampa Tracings, Olsdmar, Florida.

Wolff, G. S., Rowland, T. W., and Ellison, R. C. (1972). Surgically induced right bundle-branch block with left anterior hemiblock. An ominous sign in postoperative tetralogy of Fallot. Circulation, 46, 587-594.

Requests for reprints to Professor James $\mathrm{H}$. Moller, Box 447, University Hospitals, 420 S. E. Delaware Street, Minneapolis, Minnesota 55455, U.S.A. 